\title{
Regioselective oxygenation of fatty acids, fatty alcohols and other aliphatic compounds by a basidiomycete heme-thiolate peroxidase
}

\author{
Ana Gutiérrez ${ }^{\mathrm{a}, *}$, Esteban D. Babot ${ }^{\mathrm{a}}$, René Ullrich ${ }^{\mathrm{b}}$, Martin Hofrichter ${ }^{\mathrm{b}}$, \\ Angel T. Martínez ${ }^{\mathrm{c}}$, José C. del Río ${ }^{\mathrm{a}}$ \\ a Instituto de Recursos Naturales y Agrobiología de Sevilla, CSIC, P.O. Box 1052, E-41080 Seville, Spain \\ ${ }^{\mathrm{b}}$ Unit of Environmental Biotechnology, International Graduate School of Zittau, Markt 23, 02763 Zittau, Germany

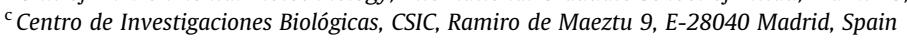

\section{A R T I C L E I N F O}

\section{Article history:}

Received 15 June 2011

and in revised form 4 August 2011

Available online 16 August 2011

\section{Keywords:}

Peroxidase/peroxygenase

Hydroxylation

Fatty acids

Fatty alcohols

Alkanes

Steroids

\begin{abstract}
A B S T R A C T
Reaction of fatty acids, fatty alcohols, alkanes, sterols, sterol esters and triglycerides with the so-called aromatic peroxygenase from Agrocybe aegerita was investigated using GC-MS. Regioselective hydroxylation of $C_{12}-C_{20}$ saturated/unsaturated fatty acids was observed at the $\omega-1$ and $\omega-2$ positions (except myristoleic acid only forming the $\omega-2$ derivative). Minor hydroxylation at $\omega$ and $\omega-3$ to $\omega-5$ positions was also observed. Further oxidized products were detected, including keto, dihydroxylated, ketohydroxy and dicarboxylic fatty acids. Fatty alcohols also yielded hydroxy or keto derivatives of the corresponding fatty acid. Finally, alkanes gave, in addition to alcohols at positions 2 or 3, dihydroxylated derivatives at both sides of the molecule; and sterols showed side-chain hydroxylation. No derivatives were found for fatty acids esterified with sterols or forming triglycerides, but methyl esters were $\omega-1$ or $\omega-2$ hydroxylated. Reactions using $\mathrm{H}_{2}{ }^{18} \mathrm{O}_{2}$ established that peroxide is the source of the oxygen introduced in aliphatic hydroxylations. These studies also indicated that oxidation of alcohols to carbonyl and carboxyl groups is produced by successive hydroxylations combined with one dehydration step. We conclude that the $A$. aegerita peroxygenase not only oxidizes aromatic compounds but also catalyzes the stepwise oxidation of aliphatic compounds by hydrogen peroxide, with different hydroxylated intermediates.
\end{abstract}

(c) 2011 Elsevier Inc. All rights reserved.

\section{Introduction}

Recently, a new peroxidase type was discovered in the woodrotting basidiomycete Agrocybe aegerita (in order Agaricales, family Bolbitaceae), which turned out to be a true peroxygenase efficiently transferring oxygen from peroxide to various organic substrates including aromatic compounds, among others [1]. The enzyme was first reported as a haloperoxidase [2], related to the chloroperoxidase of Leptoxyphium fumago [3] being able to oxidize non-phenolic aromatic compounds. However, due to its unique ability to epoxidize and hydroxylate aromatic rings by means of hydrogen peroxide, and its low halogenase activity, the enzyme is nowadays mostly referred to as an aromatic peroxygenase [4].

This peroxidase/peroxygenase is able to catalyze reactions formerly assigned to intracellular cytochrome P450 monooxygenases (P450s) [5]. However, unlike P450s, which are intracellular enzymes whose activation requires $\mathrm{NAD}(\mathrm{P}) \mathrm{H}$ as electron donor and auxiliary flavin-reductases, or a second flavin domain, for electron transfer [6], the $A$. aegerita enzyme is a secreted protein, therefore

\footnotetext{
* Corresponding author. Fax: +34 954624002.

E-mail address: anagu@irnase.csic.es (A. Gutiérrez).
}

far more stable, and only requires $\mathrm{H}_{2} \mathrm{O}_{2}$ for function [7]. This peroxidase/peroxygenase combines unique capabilities of P450s such as oxygen transfer, and classic properties of peroxidases such as oxidation of phenolic compounds, but its sequence exhibits no homology to classic peroxidases and P450s, and only little homology ( $\sim 30 \%)$ to ascomycete chloroperoxidase [8]. However, this sequence includes the conserved cysteine residue acting as the fifth heme iron ligand in the two latter enzymes and is, therefore, classified as a heme-thiolate peroxidase $[4,9]$.

The physiological function of $A$. aegerita peroxygenase remains unclear, but its extracellular location and the versatile reactions catalyzed - including peroxygenase, etherase and one-electron abstraction activities, among others - indicate that it could be involved in the unspecific oxidation and detoxification of plant (e.g., methoxylated phytoalexins) or microbial metabolites and also in the degradation of methoxylated compounds deriving from lignin and other aromatic plant sources [4]. In the latter context, it is interesting that the $A$. aegerita peroxygenase is able to oxidize non-phenolic veratryl alcohol, the typical substrate of ligninolytic peroxidases, in a broad $\mathrm{pH}$ range, while lignin peroxidase and versatile peroxidase are able to oxidize this and related aromatic compounds only under very acidic conditions (around $\mathrm{pH} 3$ ). 
The $A$. aegerita peroxygenase has recently been shown to catalyze a high number of interesting oxidation reactions, including among others, the regioselective epoxidation/hydroxylation of naphthalene, the sulfoxidation of dibenzothiophene and thioanisole, the $\mathrm{N}$-oxidation of pyridine, the $\mathrm{O}$-dealkylation of alkyl-aryl ethers, the oxidation of aryl alcohols and aldehydes and the bromination of phenol [10-13]. Although its real biological function remains uncertain as mentioned above, the $A$. aegerita peroxygenase has an enormous biotechnological potential, since selective oxo-functionalizations are among the most challenging and desired reactions in organic synthesis and, compared with P450s, has the advantage of being a self-sufficient enzyme (i.e. catalyzing oxygenations without the help of intracellular enzymes providing electrons and reducing power) [7,14]. The authors of the current study demonstrate for the first time the action of the $A$. aegerita peroxygenase on fatty acids, fatty alcohols, alkanes and steroids, and provide information on the regioselectivity and oxidation mechanism (by detailed GC-MS analyses and ${ }^{18} \mathrm{O}$-labeling) expanding the biotechnological interest of the enzyme by including the area of aliphatic hydroxylations and other oxygenation reactions.

\section{Materials and methods}

\section{Enzyme preparation}

The extracellular peroxygenase of $A$. aegerita (isoform II, $44 \mathrm{kDa}$ ) was produced and purified as described previously [2]. The enzyme preparation was homogeneous by sodium dodecylsulfate-polyacrylamide gel electrophoresis, and exhibited an $\mathrm{A}_{418} / \mathrm{A}_{280}$ ratio of 1.75 . Its specific activity was 117 units $\mathrm{mg}^{-1}$, where 1 unit represents the oxidation of $1 \mu \mathrm{mol}$ of veratryl alcohol to veratraldehyde $\left(\varepsilon_{310} 9300 \mathrm{M}^{-1} \mathrm{~cm}^{-1}\right)$ in $1 \mathrm{~min}$ at $23^{\circ} \mathrm{C}$ and $\mathrm{pH} 7$, in the presence of $2.5 \mathrm{mM} \mathrm{H}_{2} \mathrm{O}_{2}$. The turnover rate of the purified enzyme on veratryl alcohol was estimated as $85 \mathrm{~s}^{-1}$ (with a MichaelisMenten $K_{m}$ constant $\sim 2.4 \mathrm{mM}$ ).

\section{Model substrates}

Twenty-four model aliphatic substrates were used including: (i) saturated fatty acids such as lauric (dodecanoic), myristic (tetradecanoic), palmitic (hexadecanoic), stearic (octadecanoic) and arachidic (eicosanoic) acids; (ii) unsaturated fatty acids such as lauroleic (cis-9-dodecenoic), myristoleic (cis-9-tetradecenoic), palmitoleic (cis-9-hexadecenoic), oleic (cis-9-octadecenoic), linoleic (cis,cis-9,12-octadecadienoic) and gondoic (cis-11-eicosenoic) acids; (iii) fatty alcohols such as 1-tetradecanol and 1-hexadecanol; (iv) alkanes such as dodecane, tetradecane, hexadecane and octadecane; (v) free sterols such as cholesterol and sitosterol; (vi) sterol esters such as cholesteryl butyrate, cholesteryl caprylate and cholesteryl linoleate; (vii) the triglyceride trilaurin; and (viii) the fatty acid methyl ester methyl laurate. Sitosterol was purchased from Calbiochem, and all the other model substrates were obtained from Sigma-Aldrich.

\section{Enzymatic reactions}

Five milliliters reactions of the above model substrates ( $1 \mathrm{mM})$ with the A. aegerita peroxygenase $(1 \mathrm{U})$ were performed in $50 \mathrm{mM}$ sodium phosphate buffer ( $\mathrm{pH} 7$ ) at $25^{\circ} \mathrm{C}$ for $2 \mathrm{~h}$, in the presence of $2.5 \mathrm{mM} \mathrm{H}_{2} \mathrm{O}_{2}$. The substrates were previously dissolved in acetone and added to the buffer (the acetone concentration in the reaction was $15 \%$ ). In control experiments, substrates were treated under the same conditions (including $2.5 \mathrm{mM} \mathrm{H}_{2} \mathrm{O}_{2}$ ) but without enzyme. Enzymatic reactions with ${ }^{18} \mathrm{O}$-labeled hydrogen peroxide $\left(\mathrm{H}_{2}{ }^{18} \mathrm{O}_{2}\right.$,
$90 \%$ isotopic content) from Sigma-Aldrich ( $2 \%$ w:v solution) were also performed under the same conditions described above.

After the enzymatic reactions, water was immediately removed in a rotary evaporator, and the products recovered with chloroform, dried under $\mathrm{N}_{2}$, and redissolved in chloroform for GC-MS analyses. Bis(trimethylsilyl)trifluoroacetamide (Supelco) in the presence of pyridine was used to prepare trimethylsilyl derivatives.

\section{GC-MS analyses}

The GC-MS analyses were performed with a Varian 3800 chromatograph coupled to an ion-trap detector (Varian 4000) using a medium-length fused-silica DB-5HT capillary column $(12 \mathrm{~m} \times$ $0.25 \mathrm{~mm}$ internal diameter, $0.1 \mu \mathrm{m}$ film thickness) from J\&W Scientific, enabling simultaneous elution of the different compound classes [15]. The oven was heated from $120^{\circ} \mathrm{C}(1 \mathrm{~min})$ to $380^{\circ} \mathrm{C}$ at $10^{\circ} \mathrm{C} \mathrm{m^{-1 }}$, and held for $5 \mathrm{~min}$. Other temperature program, from $50{ }^{\circ} \mathrm{C}$ to $110^{\circ} \mathrm{C}$ (at $30^{\circ} \mathrm{C} \mathrm{min}^{-1}$ ) and then to $320^{\circ} \mathrm{C}\left(\right.$ at $6{ }^{\circ} \mathrm{C} \mathrm{min}^{-1}$ ), was used when necessary. In all GC-MS analyses, the transfer line was kept at $300^{\circ} \mathrm{C}$, the injector was programmed from $120^{\circ} \mathrm{C}$ ( $0.1 \mathrm{~min})$ to $380^{\circ} \mathrm{C}$ at $200^{\circ} \mathrm{C} \mathrm{min}{ }^{-1}$ and held until the end of the analysis, and helium was used as carrier gas at a rate of $2 \mathrm{ml} \mathrm{min}^{-1}$.

Compounds were identified by mass fragmentography, and by comparing their mass spectra with those of the Wiley and NIST libraries and standards, and quantitation was obtained from total-ion peak area, using response factors of the same or similar compounds (those of the saturated substrates and derivatives being in general higher than those of the unsaturated ones). Single-ion chromatographic profiles (of base or other specific ions) were used to estimate compound abundances when two peaks partially overlapped. The relative abundance of products incorporating $1-3{ }^{18} \mathrm{O}_{2}$ atoms in the $\mathrm{H}_{2}{ }^{18} \mathrm{O}_{2}$ reactions described above was estimated by peak integration using the corresponding ion with 2,4 or $6 \mathrm{~m} / z$ increase (with correction from interfering ions in $\mathrm{H}_{2}{ }^{16} \mathrm{O}_{2}$ spectra, when required).

\section{Results}

Twenty-four model aliphatic substrates, including a series of saturated and unsaturated fatty acids, one fatty acid methyl ester, and several fatty alcohols, alkanes, free and esterified sterols and triglycerides were treated with the A. aegerita peroxygenase. All the fatty acids and fatty alcohols showed reactivity towards the enzyme. Among the alkanes, only those of shorter chain length were modified. The free sterols were only slightly modified, and the esterified sterols and triglycerides showed no reactivity. The conversion rate, and the reaction products formed were studied by GC-MS as described below.

\section{Fatty acid oxidation studies}

Eleven fatty acids with even carbon number from $C_{12}$ to $C_{20}$ were tested as substrates of the $A$. aegerita peroxygenase (Table 1 ). All the saturated fatty acids showed reactivity towards the enzyme, although at different extents depending on the chain length, the order of activity as hydroxylation substrates being $\mathrm{C}_{12}>\mathrm{C}_{14}>\mathrm{C}_{16}>\mathrm{C}_{18}>\mathrm{C}_{20}$. Six unsaturated fatty acids with the same length as the saturated ones were also tested, all of them being more active than their saturated analogs. It should be mentioned that differences in solubility among the several substrates tested, related to chain length and presence of double bonds, could also influence substrate conversion.

For all the fatty acids, with the exception of myristoleic acid, the alkyl chains were monohydroxylated to give predominantly mixtures of the $\omega-1$ and $\omega-2$ isomers (Fig. 1). The position of the hydroxyl group was determined by the mass spectra of their 
Table 1

Conversion of different types of aliphatic compounds by the A. aegerita peroxygenase (\% of initial content).

\begin{tabular}{|c|c|}
\hline \\
\hline \multicolumn{2}{|l|}{$\begin{array}{l}\text { Fatty acids } \\
\text { Lauric acid }\left(\mathrm{C}_{12}\right)\end{array}$} \\
\hline Lauroleic acid $\left(\mathrm{C}_{12: 1}\right)$ & 42 \\
\hline Myristic acid $\left(\mathrm{C}_{14}\right)$ & 26 \\
\hline Myristoleic acid $\left(C_{14: 1}\right)$ & 44 \\
\hline Palmitic acid $\left(\mathrm{C}_{16}\right)$ & 24 \\
\hline Palmitoleic acid $\left(C_{16: 1}\right)$ & 42 \\
\hline Estearic acid $\left(\mathrm{C}_{18}\right)$ & 9 \\
\hline Oleic acid $\left(\mathrm{C}_{18: 1}\right)$ & 29 \\
\hline Linoleic acid $\left(\mathrm{C}_{18: 2}\right)$ & 30 \\
\hline Arachidic acid $\left(C_{20}\right)$ & $<5$ \\
\hline Gondoic acid $\left(C_{20: 1}\right)$ & 23 \\
\hline \multicolumn{2}{|l|}{ Fatty acid methyl ester } \\
\hline Methyl laurate & 56 \\
\hline \multicolumn{2}{|l|}{ Fatty alcohols } \\
\hline 1-Tetradecanol & 41 \\
\hline 1-Hexadecanol & 15 \\
\hline \multicolumn{2}{|l|}{ Alkanes } \\
\hline Dodecane & $<5$ \\
\hline Tetradecane & $<5$ \\
\hline Hexadecane & $<5$ \\
\hline Octadecane & 0 \\
\hline \multicolumn{2}{|l|}{ Sterols } \\
\hline Cholesterol & $<5$ \\
\hline Sitosterol & $<5$ \\
\hline \multicolumn{2}{|l|}{ Sterol esters } \\
\hline Cholesteryl butyrate & 0 \\
\hline Cholesteryl caprylate & 0 \\
\hline Cholesteryl linoleate & 0 \\
\hline \multicolumn{2}{|l|}{ Triglyceride } \\
\hline Trilaurin & 0 \\
\hline
\end{tabular}

trimethylsilyl derivatives, as illustrated in Fig. 2 for $(\omega-1)$ and $(\omega-2)$-hydroxymyristic acid. These spectra show prominent ions from $\alpha$-cleavage of the molecular backbone on both sides of the trimethylsilyl group, with characteristic fragments at $\mathrm{m} / \mathrm{z} 117$ and $\left[\mathrm{M}-\mathrm{CH}_{3}\right]^{+}$for the $(\omega-1)$-hydroxyfatty acids $(\mathrm{m} / z 373$ for 13hydroxymyristic acid, Fig. $2 \mathrm{~A}$ ) and at $\mathrm{m} / z \mathrm{z} 131$ and $\left[\mathrm{M}-\mathrm{CH}_{3} \mathrm{CH}_{2}\right]^{+}$ for the ( $\omega-2)$-hydroxyfatty acids ( $m / z 359$ for 12-hydroxymyristic acid, Fig. 2B). In all cases, no molecular ions were observed, although they could be readily determined from the fragment corresponding to the loss of a methyl from the trimethylsilyl group $\left[\mathrm{M}-\mathrm{CH}_{3}\right]^{+}(\mathrm{m} / z 373$ in both hydroxymyristic acid isomers, Fig. 2).

The formation of $\omega-1$ and $\omega-2$ derivatives decreased with increasing chain length especially in case of saturated fatty acids (Fig. 1). Surprisingly, myristoleic acid formed the $\omega-2$ but not the $\omega-1$ isomer (it was the only fatty acid assayed that did not formed this hydroxylated isomer). On the other hand, the $\omega-3$ to $\omega-5$ and especially the $\omega$ positions were also hydroxylated, although with extremely lower efficiency than the $\omega-1$ and $\omega-2$ positions (Table 2) being detected in trace amounts in most cases. Hydroxylation beyond the $\omega-5$ position was never observed. Dicarboxylic acids were also detected indicating oxidation of the terminal methyl group, followed by oxidation of the primary alcohol formed to the corresponding acid group.

An ${ }^{18} \mathrm{O}$-labeling study, using myristic acid as substrate, and either $\mathrm{H}_{2}{ }^{18} \mathrm{O}_{2}$ or $\mathrm{H}_{2}{ }^{16} \mathrm{O}_{2}$ as enzyme cosubstrate, was performed to investigate the origin of the oxygen incorporated during the oxygenation of fatty acids. In the reaction using $\mathrm{H}_{2}{ }^{18} \mathrm{O}_{2}$, mass spectral analysis of the resulting monohydroxylated fatty acids showed that characteristic fragments for the $(\omega-1)$-hydroxyfatty acid had $\sim 90 \%$ shifted from the natural abundance $\mathrm{m} / \mathrm{z} 117$ and $\mathrm{m} / \mathrm{z} 373$ found in the unlabeled peroxide reaction (Fig. 2A) to $m / z 119$ and $m / z 375$ (Fig. 3A), respectively. Likewise, the characteristic fragments for the $(\omega-2)$-hydroxyfatty acid shifted from the natural abundance $m / z 131$ and $m / z 359$ found in the unlabeled peroxide reaction (Fig. 2B) to $m / z 133$ and $m / z 361$ (Fig. 3B), respectively. In both hydroxyfatty acids, $\sim 10 \%$ of the original fragments remained in the $\mathrm{H}_{2}{ }^{18} \mathrm{O}_{2}$ reactions due to the $90 \%{ }^{18} \mathrm{O}$ isotopic purity of the labeled peroxide used.

In addition to hydroxylated derivatives, keto derivatives at positions $\omega-1$ and $\omega-2$ were also identified (Fig. 1 ). The position of the carbonyl group was determined by the mass spectra of the trimethylsilyl derivatives, as shown in Fig. 2C and D for $(\omega-1)$ and $(\omega-2)$-ketomyristic acid, respectively. No molecular ions were observed in the mass spectra, although they could be determined from the $\left[\mathrm{M}-\mathrm{CH}_{3}\right]^{+}$fragment ( $\mathrm{m} / z 299$ in both ketomyristic acids). Additional losses of the methylketo $\left[\mathrm{M}-\mathrm{CH}_{3}-\mathrm{CH}_{3} \mathrm{CO}\right]^{+}$or ethylketo $\left[\mathrm{M}-\mathrm{CH}_{3}-\mathrm{CH}_{3} \mathrm{CH}_{2} \mathrm{CO}\right]^{+}$groups from $\alpha$-cleavage of the carbonyl group in $(\omega-1)$ and $(\omega-2)$-ketofatty acids, respectively, produced other diagnostic fragments (at $m / z 257$ for 13-ketomyristic acid, and $m / z 243$ for 12-ketomyristic acid). Another characteristic fragments resulted from the loss of a water molecule $\left[\mathrm{M}-\mathrm{CH}_{3}-\mathrm{H}_{2} \mathrm{O}\right]^{+}$ (at $m / z 281$ in both ketomyristic acid isomers). The ratio between the two main isomers $(\omega-1 / \omega-2)$ among the total monooxygenated derivatives (hydroxy and ketofatty acids) for the different compounds assayed is shown in Table 2 . This ratio was very similar for all the saturated fatty acids (from 1.2 to 1.6). Unsaturated fatty acids often showed lower ratios (ranging from 0.6 to 1.2 ) with the exception of linoleic acid (1.7 ratio), and myristoleic acid that only formed the $\omega-2$ derivative.

In the enzyme-catalyzed reaction of myristic acid with $\mathrm{H}_{2}{ }^{18} \mathrm{O}_{2}$, mass spectral analysis of the $(\omega-1)$ and $(\omega-2)$-ketofatty acids formed (together with the same hydroxyfatty acids) showed that the above mentioned $\left[\mathrm{M}-\mathrm{CH}_{3}\right]^{+}$fragment (shared by both keto isomers) had $\sim 10 \%$ shifted from the natural abundance $m / z 299$ found in the unlabeled peroxide reaction (Fig. 2) to $\mathrm{m} / \mathrm{z} 301$ (spectrum not shown). This ${ }^{18} \mathrm{O}$-labeling is much lower than the $90 \%$ observed during formation of the corresponding hydroxyfatty acids, and revealed ${ }^{18} \mathrm{O}$ loss from the carbonyl formed, due to hydroxyl exchange with water.

Further oxygenation/oxidation of the above mono-substituted hydroxy and keto derivatives were observed in the enzymatic reactions with fatty acids, including dihydroxylated compounds and several combinations of keto and hydroxy derivatives. The chemical structures of all the fatty acid derivatives identified in the different enzymatic reactions performed are shown in Supplementary data, SD, Fig. S1.

With the aim of investigating whether it was necessary that the carboxyl group was in free form for enzyme activity, methyl laurate was assayed as substrate. The results showed that the enzyme is able to transform the methyl esters (Table 1). Like in the reaction with free lauric acid, the reaction gave two main monohydroxylated derivatives at $\omega-1$ and $\omega-2$ positions, with a $\omega-1 / \omega-2$ ratio of 1.3 (similar to that obtained for the free fatty acids).

\section{Fatty alcohol oxidation studies}

Two primary fatty alcohols (1-tetradecanol and 1-hexadecanol) were assayed as substrates for the A. aegerita peroxygenase (Table 1). Among the reaction products identified (Fig. 4 and Fig. S2 of SD), the presence of the corresponding fatty acids (myristic and palmitic acids, respectively) is noteworthy. The majority of the additional products were hydroxy or keto derivatives at $\omega-1$ and $\omega-2$ positions of the fatty acids ( $\omega$-hydroxymyristic and $\omega$ hydroxypalmitic acids were also identified). The $\omega-1 / \omega-2$ ratio of these monooxygenated derivatives was 1.4 (similar to that obtained directly from myristic and palmitic acids). Some minor peaks were tentatively assigned to monohydroxylated (and keto) derivatives of the fatty alcohols at $\omega-1$ and $\omega-2$ positions, which 

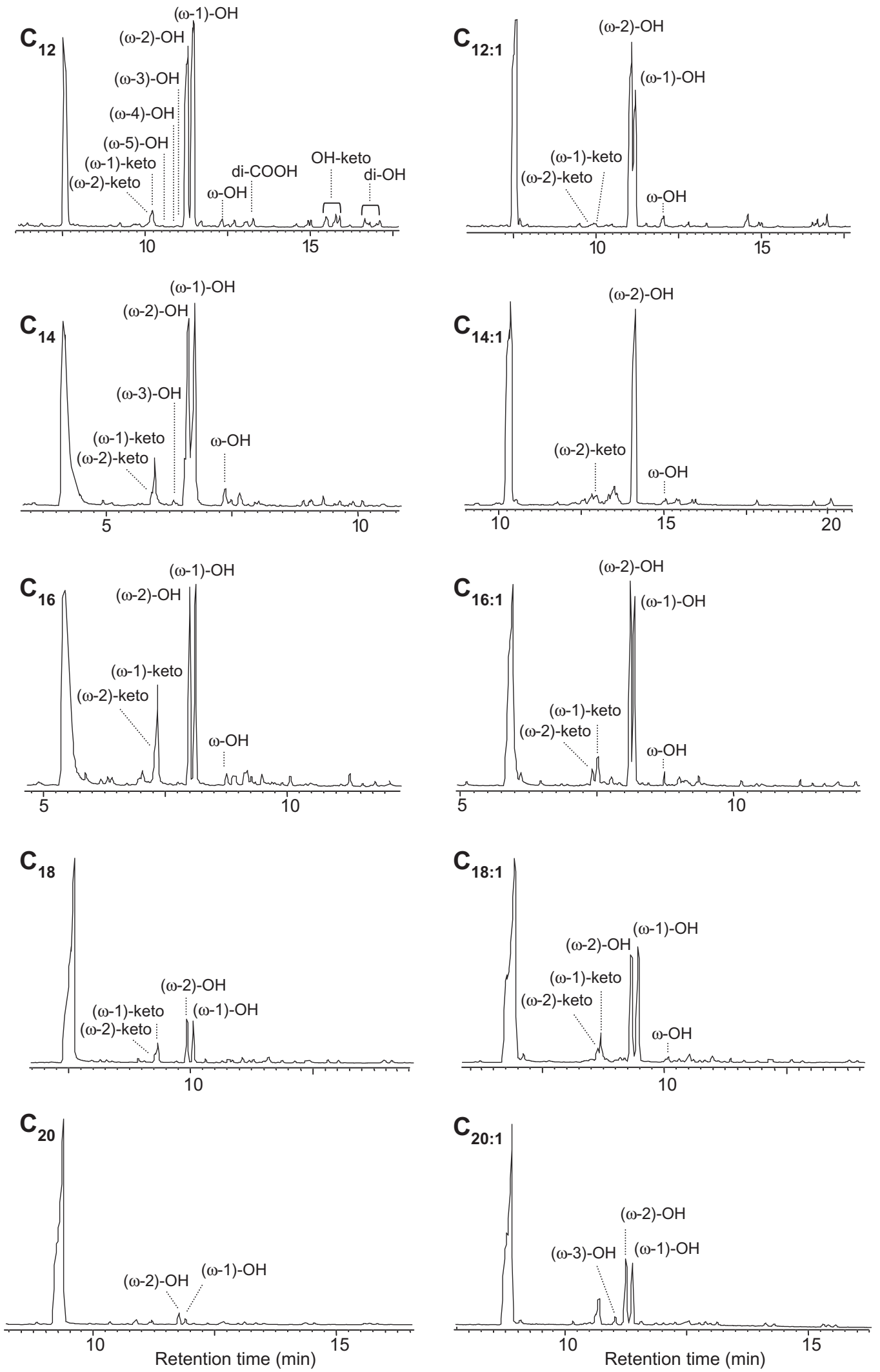

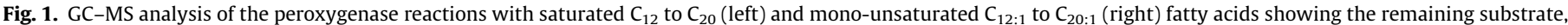

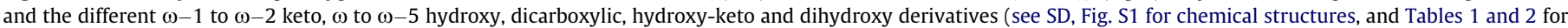
quantitative values). The most adequate chromatographic program was used in each case.

were more evident in the reaction with tetradecanol. Only traces of the corresponding aldehydes were observed in the reactions.
${ }^{18} \mathrm{O}$-labeling studies were also performed in the reactions of 1-tetradecanol with the enzyme (and similar results were 

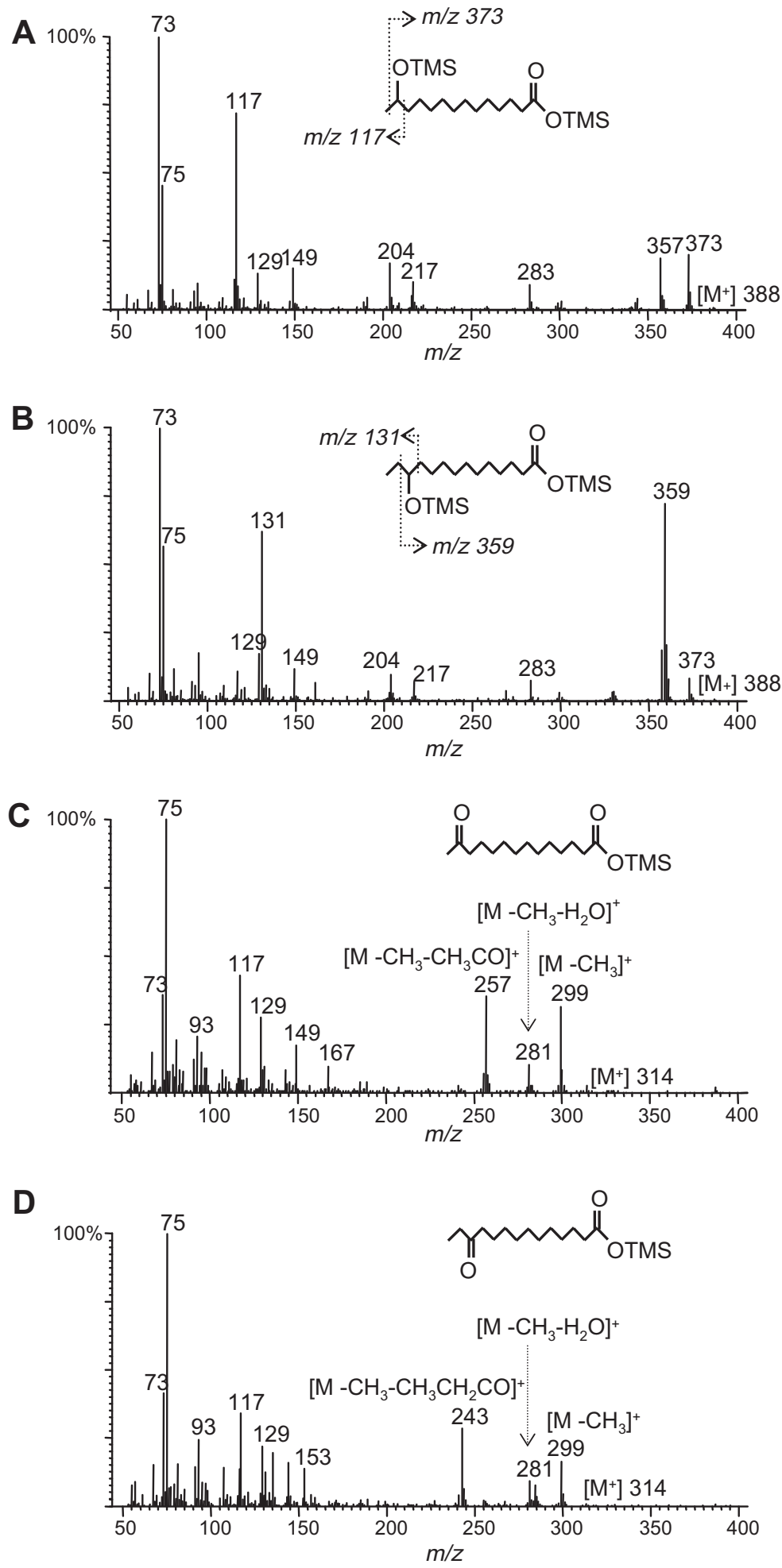

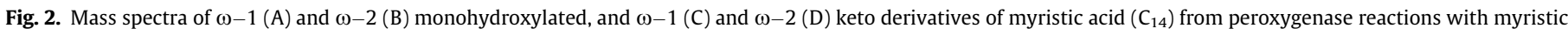
acid, as trimethylsilyl (TMS) derivatives.

obtained in the 1-hexadecanol reactions). Incorporation of ${ }^{18} \mathrm{O}$ from $\mathrm{H}_{2}{ }^{18} \mathrm{O}_{2}$ to the carboxyl group was observed during the oxidation of 1-tetradecanol to myristic acid (Fig. 5). Mass spectral analysis of the myristic acid formed, showed that the characteristic fragment at $\left[\mathrm{M}-\mathrm{CH}_{3}\right]^{+}$had shifted from the natural abundance $\mathrm{m} / \mathrm{z} 285$ found in the unlabeled peroxide reaction (Fig. 5A) to $\mathrm{m} / \mathrm{z} 289$ (incorporation of two ${ }^{18} \mathrm{O}$ atoms at the carboxyl group) and $\mathrm{m} / \mathrm{z} 287$ (incorporation of one ${ }^{18} \mathrm{O}$ atom at the carboxyl group) (Fig. 5B). The relative abundances of the ${ }^{18} \mathrm{O}$ mono (74\%) and bilabeled (16\%) myristic acid, estimated from the corresponding fragment peak areas, are included in Fig. $5 \mathrm{~B}$, together with their formulae $(10 \%$ unlabeled acid was also formed due to the partial isotopic purity of the peroxide used). 
Table 2

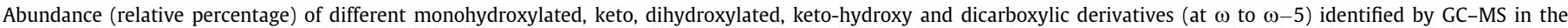

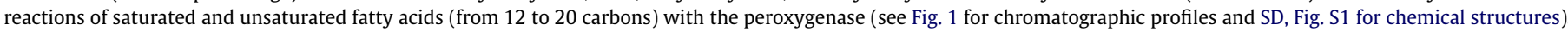
and $\omega-1 / \omega-2$ ratio of the main (monooxygenated) products formed.

\begin{tabular}{|c|c|c|c|c|c|c|c|c|c|c|c|c|}
\hline & $\omega \mathrm{OH}$ & $\omega-1 \mathrm{OH}$ & $\omega-2 \mathrm{OH}$ & $\omega-3 \mathrm{OH}$ & $\omega-4 \mathrm{OH}$ & $\omega-5 \mathrm{OH}$ & $\omega-1$ keto & $\omega-2$ keto & $\mathrm{di}-\mathrm{OH}$ & OH-keto & $\mathrm{di}-\mathrm{COOH}$ & $\omega-1 / \omega-2$ \\
\hline $\mathrm{C}_{12}$ & 1.3 & 39.7 & 32.0 & 0.2 & $<0.1$ & $<0.1$ & 5.8 & 1.0 & 4.4 & 15.5 & 0.3 & 1.4 \\
\hline$C_{12: 1}$ & 3.3 & 37.4 & 59.2 & 0 & 0 & 0 & $<0.1$ & $<0.1$ & 0 & 0 & 0 & 0.6 \\
\hline $\mathrm{C}_{14}$ & 3.5 & 34.4 & 30.5 & 0.3 & 0 & 0 & 20.8 & 3.3 & 0.5 & 6.2 & 0.6 & 1.6 \\
\hline$C_{14: 1}$ & 1.8 & 0 & 94.6 & 0 & 0 & 0 & 0 & 3.6 & 0 & 0 & 0 & 0 \\
\hline$C_{16}$ & 1.4 & 23.6 & 23.6 & 0.3 & 0 & 0 & 34.5 & 16.3 & 0 & 0 & 0.3 & 1.5 \\
\hline$C_{16: 1}$ & 2.5 & 35.7 & 47.0 & 0.1 & 0 & 0 & 10.4 & 4.4 & 0 & 0 & 0 & 0.9 \\
\hline $\mathrm{C}_{18}$ & $<0.1$ & 22.7 & 27.0 & 0.1 & 0 & 0 & 32.8 & 17.0 & 0 & 0 & 0.5 & 1.3 \\
\hline$C_{18: 1}$ & 1.6 & 40.8 & 39.0 & 0.2 & 0 & 0 & 13.0 & 5.3 & 0 & 0 & 0 & 1.2 \\
\hline$C_{18: 2}$ & 1.0 & 50.2 & 33.5 & 2.5 & 0 & 0 & 10.0 & 2.9 & 0 & 0 & 0 & 1.7 \\
\hline $\mathrm{C}_{20}$ & $<0.1$ & 16.0 & 28.1 & 0 & 0 & 0 & 38.7 & 17.3 & 0 & 0 & 0 & 1.2 \\
\hline $\mathrm{C}_{20: 1}$ & 1.2 & 35.0 & 38.7 & 0.4 & 0 & 0 & 18.8 & 6.0 & 0 & 0 & 0 & 1.2 \\
\hline
\end{tabular}
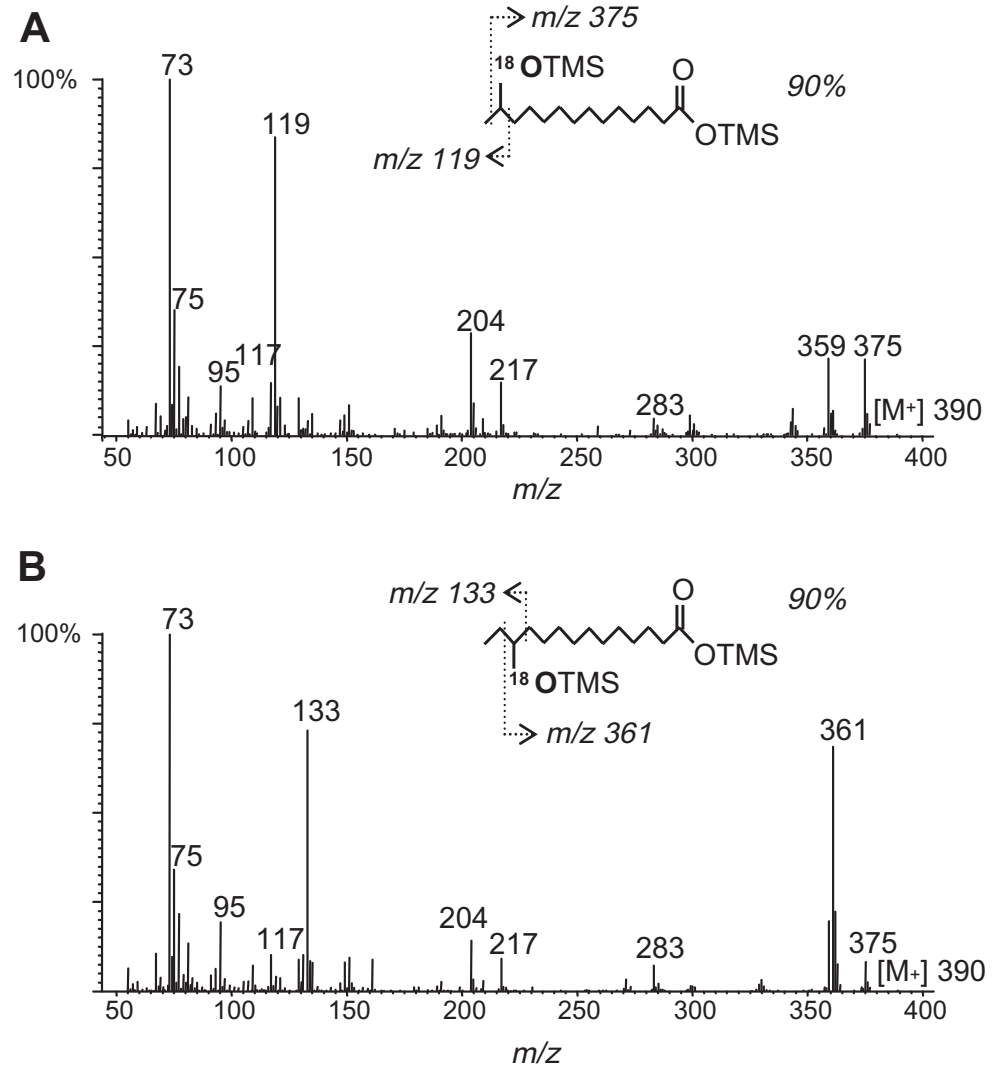

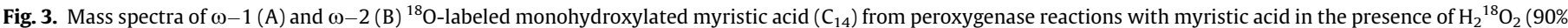
isotopic purity) as trimethylsilyl (TMS) derivatives.

The incorporation of ${ }^{18} \mathrm{O}$ from $\mathrm{H}_{2}{ }^{18} \mathrm{O}_{2}$ was also evidenced in the mass spectra of the $\omega-1$ or $\omega-2$ hydroxylated derivatives of myristic acid, formed in the same 1-tetradecanol reaction. The mass spectral analysis showed that the characteristic fragments for the $(\omega-1)$ and $(\omega-2)$-hydroxylated derivatives of fatty acids had $\sim 90 \%$ shifted from the natural abundance $m / z 117$ and $m / z$ 131 to $\mathrm{m} / \mathrm{z} 119$ and $\mathrm{m} / \mathrm{z} 133$, respectively (spectra not shown) due to peroxide ${ }^{18} \mathrm{O}$ incorporation. Moreover, the characteristic fragments for the $\omega-1$ at $\left[\mathrm{M}-\mathrm{CH}_{3}\right]^{+}$had shifted from the natural abundance $\mathrm{m} / \mathrm{z} 373$ found in the unlabeled peroxide reaction (Fig. 6A) to $m / z 379$ (incorporation of three ${ }^{18} \mathrm{O}$ atoms), $\mathrm{m} / \mathrm{z} 377$ (incorporation of two ${ }^{18} \mathrm{O}$ atoms) and $\mathrm{m} / \mathrm{z} 375$ (incorporation of one ${ }^{18} \mathrm{O}$ atom) (Fig. 6C). Likewise, the characteristic fragments for the $\omega-2$ at $\left[\mathrm{M}-\mathrm{CH}_{3} \mathrm{CH}_{2}\right]^{+}$(including both the hydroxyl and carboxyl groups) had shifted from the natural abundance $m / z 359$ found in the unlabeled peroxide reaction (Fig. 6B) to $m / z 365, m /$ $z 363$ and $m / z 361$ (Fig. 6D). The relative abundances of the ${ }^{18} \mathrm{O}$ mono-, bi- and tri-labeled hydroxymyristic acid, estimated from the corresponding fragment peak areas, are also included in Fig. 6C ( $\omega-1$ isomer) and Fig. 6D ( $\omega-2$ isomer), together with their formulae and fragment generation ( $0-2 \%$ unlabeled hydroxyacid was also formed).

\section{Alkane oxidation studies}

Four saturated alkanes (dodecane, tetradecane, hexadecane and octadecane) were tested as A. aegerita peroxygenase substrates ( $\mathrm{Ta}$ ble 1). No reactivity with octadecane was observed under the experimental conditions used. It should be noted that hydroxylation of fatty acids with the same chain length $\left(C_{18}\right)$ was observed. 


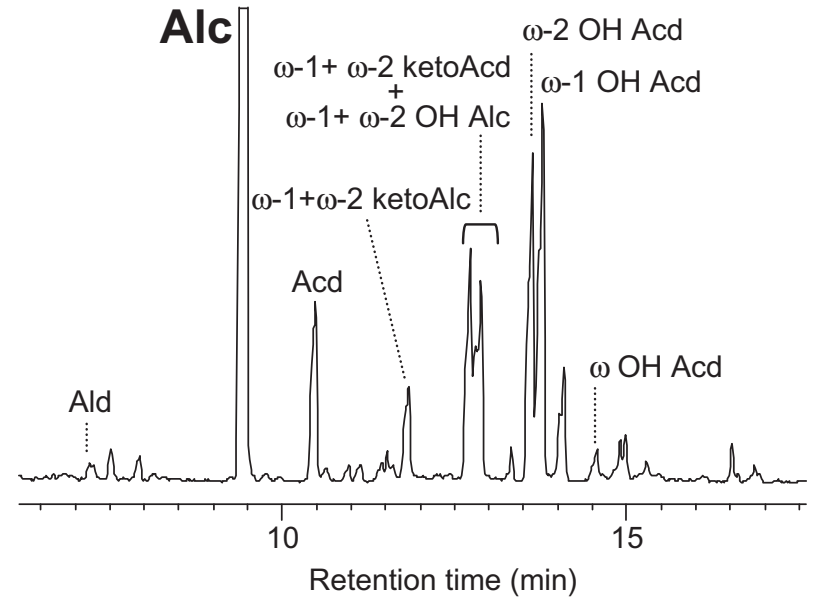

Fig. 4. GC-MS analysis of the peroxygenase reaction with tetradecanol, showing the remaining fatty alcohol substrate (Alc), the corresponding fatty acid (Acd) and its different $\omega-1$ and $\omega-2$ keto, and $\omega$ to $\omega-2$ hydroxy derivatives formed (see SD, Fig. S2 for chemical structures, and Table 1 for quantitative values). Other minor compounds such as $\omega-1$ and $\omega-2$ keto and hydroxy derivatives of the tetradecanol and traces of the aldehyde (Ald) are also shown.

In contrast, the reactions with dodecane, gave monohydroxylated derivatives at positions 2 and 3 . In addition to the monohydroxylated derivatives, products dihydroxylated at the positions 2 and 3 from both ends of the molecule (i.e. $\alpha+1$ and $\omega-1 / \omega-2$, or $\alpha+2$ and $\omega-1 / \omega-2)$ were identified as the predominant compounds. Several combinations of keto and hydroxy derivatives were also formed although in minor amounts (see SD, Fig. S3). Unlike that observed in the reactions with fatty acids and fatty alcohols, terminal hydroxylation was not general in the reactions with alkanes. Similar derivatives to those found for dodecane were obtained from tetradecane and hexadecane although in lower amounts.

\section{Steroid oxidation studies}

Reactions of both free (cholesterol and sitosterol) and esterified (cholesteryl butyrate, caprylate and linoleate) sterols with the $A$.

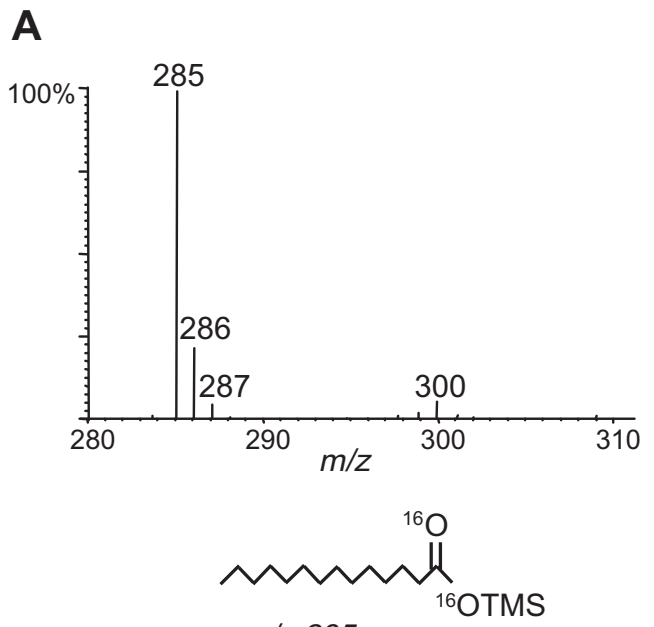

$m / z 285$ aegerita peroxygenase were studied (Table 1). The enzyme showed low reactivity with free sterols, and only a very low conversion rates were attained under the experimental conditions used. The reaction products of cholesterol were monohydroxylated derivatives at positions C-24, C-25, and C-26 (or C-27) (see SD, Fig. S4A) with monohydroxylated C-25 predominating (see SD, Fig. S4B). In the reaction with sitosterol, only the monohydroxylated derivatives at positions C-24 and C-25 were observed. On the other hand, in the reactions with cholesterol esters no derivatives were observed.

\section{Triglyceride oxidation studies}

In addition of testing the reactivity of free lauric acid and lauric acid methyl ester, the peroxygenase reaction with a glycerol ester of lauric acid (trilaurin) was also studied. Unlike the reaction of free and methylated fatty acid, the triglyceride reaction did not yield any product.

\section{Discussion}

\section{A. aegerita peroxygenase and other heme-thiolate enzymes}

Heme-containing enzymes using $\mathrm{H}_{2} \mathrm{O}_{2}$ as electron acceptor (peroxidases) are a fascinating group of biocatalysts with a variety of ecological and biotechnological implications [9]. The current work deals with one of the most novel hemeperoxidase types, the socalled aromatic peroxygenase, that catalyze remarkable reactions such as peroxide-driven oxygen transfer, together with typical peroxidase reactions, being part of a separate peroxidase superfamily for which the name heme-thiolate peroxidases has been suggested $[4,9,16]$. A similar heme pocket is shared by P450s and results in similar ability to catalyze monooxygenation reactions, although $\mathrm{P} 450$ s use $\mathrm{O}_{2}$ as electron acceptor. However, the so-called "peroxideshunt" exceptionally operates in some of them [17], and an unusual P450 being preferentially activated by $\mathrm{H}_{2} \mathrm{O}_{2}$ has been described [18]. The main difference between the $\mathrm{P} 450$ s and peroxygenase reactions concerns formation of the cofactor reactive Compound I, a porphyrin (P) cation-radical $\mathrm{Fe}^{4+}=0$ complex, that in peroxidases results from

\section{B}

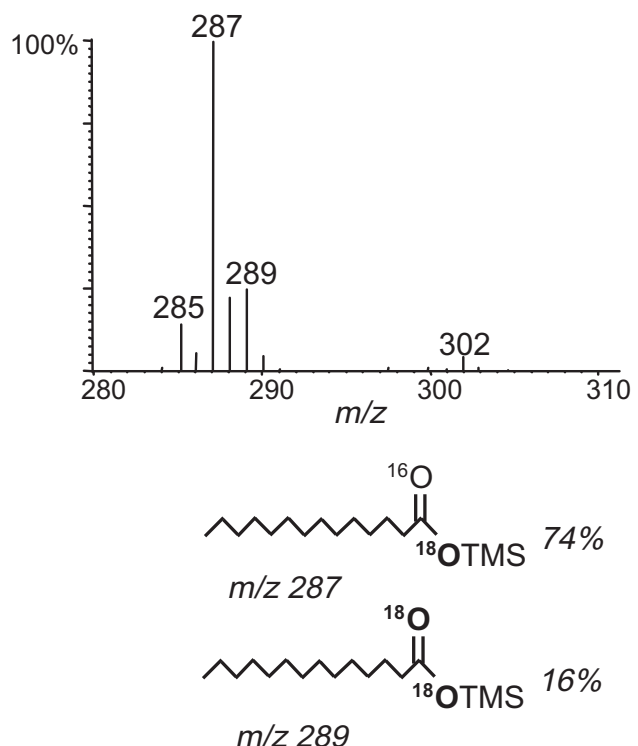

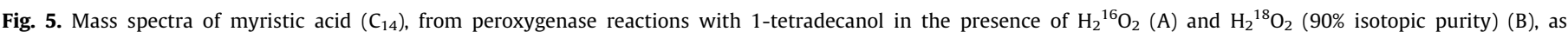

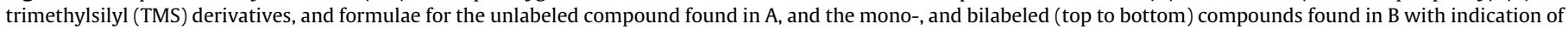
their characteristic ions and relative abundances (10\% unlabeled acid was also found in the second reaction). 

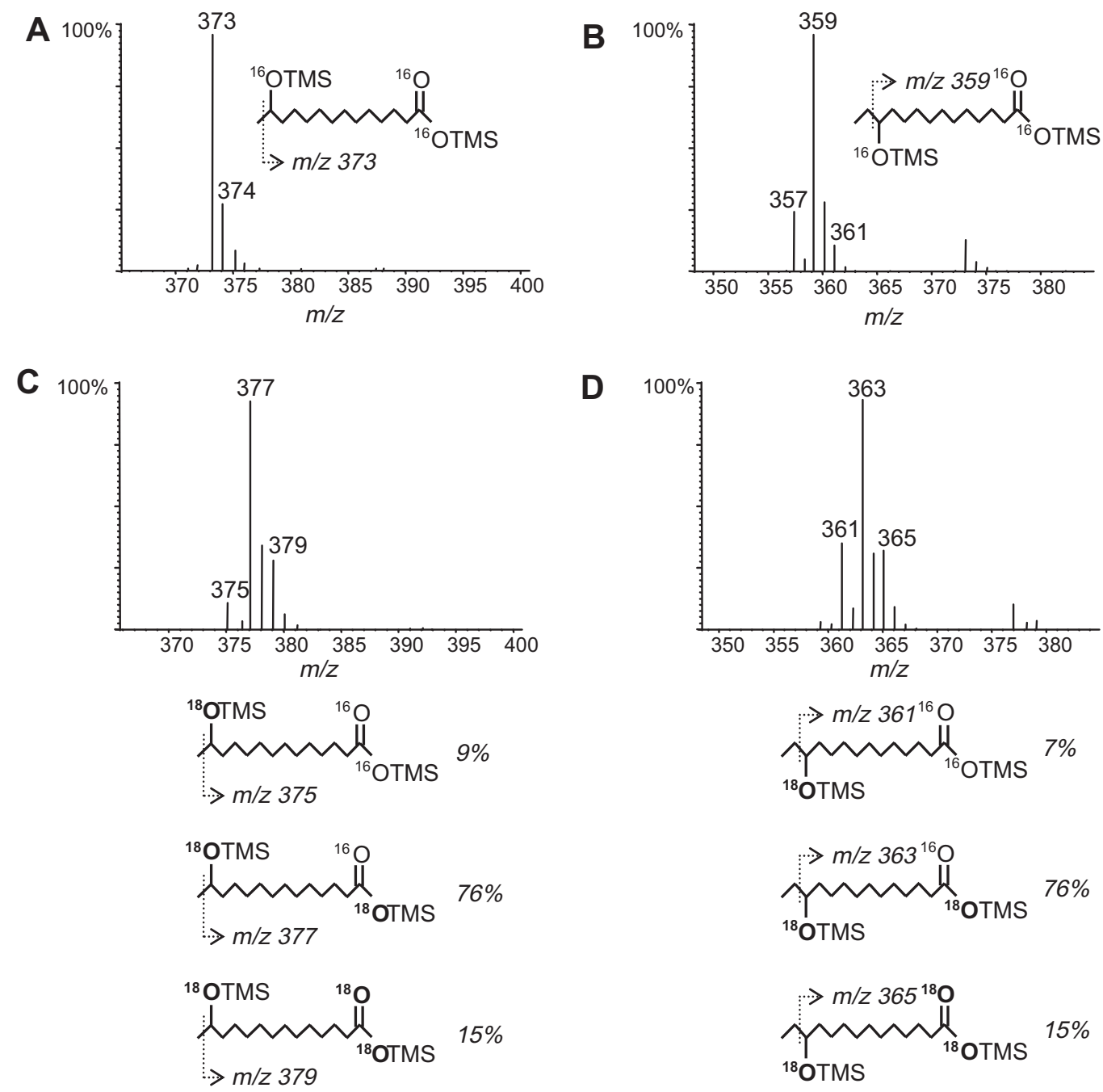

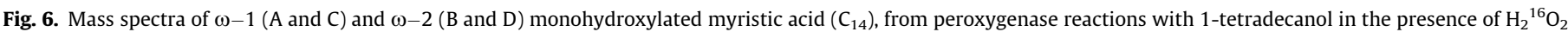

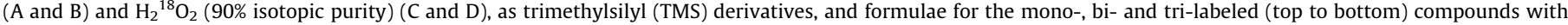
indication of their characteristic ions and relative abundances in the $\omega-1(\mathrm{C})$ and $\omega-2$ (D) isomers of hydroxymyristic acid (0-2\% unlabeled product was also found).

$\mathrm{H}_{2} \mathrm{O}_{2}$ generated by oxidases (as shown in Eq. (1) for the peroxygenase reaction with ${ }^{18} \mathrm{O}$-labeled peroxide); while $\mathrm{P} 450$ s directly react with $\mathrm{O}_{2}$ receiving electrons from an associated flavoprotein (or a flavo-domain) $[4,19,20]$. The subsequent reaction in normal peroxidases involves successive one-electron abstractions from two substrate molecules, while in P450 monooxygenases, and also in peroxygenases, consists of a first hydrogen-atom abstraction (by $\mathrm{Fe}^{4+}=0$ ) coupled to oxygen rebound with hydroxyl transfer to the substrate (regenerating the neutral-porphyrin/ferric resting-state enzyme)(Eq. (2)). The significant deuterium isotopic effect observed in peroxygenase reactions [21] supports the hydrogen abstraction mechanism.

$$
\begin{aligned}
& \mathrm{P}-\mathrm{Fe}^{3+}+\mathrm{H}_{2}{ }^{18} \mathrm{O}_{2} \rightarrow \mathrm{P}-\mathrm{Fe}^{3+}\left[\mathrm{O}-{ }^{18} \mathrm{OH}\right]^{-}+\mathrm{H}^{+} \rightarrow \mathrm{P}^{+\cdot}-\mathrm{Fe}^{4+} \\
& ={ }^{18} \mathrm{O}_{(\mathrm{C}-\mathrm{I})}+\mathrm{H}_{2} \mathrm{O} \\
& \mathrm{P}^{+\cdot}-\mathrm{Fe}^{4+}={ }^{18} \mathrm{O}_{(\mathrm{C}-\mathrm{I})}+\mathrm{H}-\mathrm{R} \rightarrow\left[\mathrm{P}-\mathrm{Fe}^{4+}-{ }^{18} \mathrm{O} \ldots \mathrm{H} \ldots \mathrm{R}\right] \\
& \rightarrow \mathrm{P}^{-\mathrm{Fe}^{3+}}+\mathrm{H}^{18} \mathrm{O}-\mathrm{R}
\end{aligned}
$$

After the first aromatic peroxygenase discovered in A. aegerita [2], similar enzymes have been isolated from other basidiomycetes $[4,10,22]$, and genes of heme-thiolate peroxidases have been identified in different basidiomycete genomes [23-25]. Analysis of the sequences available to date suggests several sub-types in this superfamily, the $A$. aegerita heme-thiolate peroxidase being close to five heme-thiolate peroxidase genes identified in the Coprinopsis cinerea genome. Interestingly, the best characterized heme-thiolate peroxidase, the ascomycete $L$. fumago chloroperoxidase, does not cluster together with the basidiomycete heme-thiolate peroxidases. The present study shows that the extracellular peroxygenase from $A$. aegerita, previously known as catalyzing $\mathrm{H}_{2} \mathrm{O}_{2}$-dependent hydroxylations and halogenations of aromatic substrates [1,2], is able to catalyze the regioselective oxygenation/oxidation of different aliphatic compounds, strongly broadening the biotechnological interest of the enzyme, as shown by the new patents deposited.

Oxygenation/oxidation of different types of aliphatic compounds by A. aegerita peroxygenase

The A. aegerita peroxygenase shows prominent activity on a wide range of fatty acids yielding a variety of monohydroxylated, keto and dicarboxylic derivatives (and is also active on their methyl esters). P450s also catalyze fatty acid hydroxylations, as reported for Bacillus megaterium P450BM-3 [26]. Under certain conditions, the monohydroxylated isomers from palmitic acid, unlike those from lauric and myristic acids, were further metabolized by P450BM-3 to secondary and tertiary (hydroxy-keto) products. 
In the peroxygenase reactions, oxidation of hydroxyfatty acids to ketones, diols and hydroxy-ketones was observed with all the fatty acids tested.

The $A$. aegerita peroxygenase also showed oxygenation activity on fatty alcohols, alkanes and free sterols. The activity on alkanes was the lowest among the simple aliphatic compounds assayed. Alkane hydroxylating activity was not observed in wild-type P450BM3 [27] but a variant after several rounds of directed evolution was able to hydroxylate alkanes [28]. In the peroxygenase reactions with fatty alcohols, most products were hydroxy or keto derivatives of the corresponding fatty acids, and only a minor part of the fatty alcohols. This differs from the reaction of 1-hexadecanol with P450BM-3, where the only products identified were isomers of hexadecanediol [27]. Moreover, no hydroxylation at the $\omega$ position was observed, while $\omega$-hydroxyfatty acids were identified here.

When the reactions with simple aliphatic compounds are taken together, it becomes apparent that the $A$. aegerita peroxygenase would be able to catalyze the stepwise oxygenation of fatty alcohols (or even alkanes) to keto and dicarboxylic acids via fatty alcohols and acids, including different hydroxylated intermediates. In P450s, similar cascade oxidations are also produced, although the variety of products formed is lower $[29,30]$.

In the sterol reactions, the conversion rates were very low and limited to the aliphatic side-chain. Maybe the side-chain enters into the same site where alkanes are oxidized in the $A$. aegerita peroxygenase, while P450s have a specific site where steroids are efficiently oxidized [31]. In contrast, the aliphatic chains in sterol esters and triglycerides were not oxidized. Taking into account that the same acids in free form (and also methyl laurate) are substrates of the A. aegerita enzyme, there is seemingly a limitation in molecular size concerning bulky substrate hydroxylation.

Regioselective oxygenation of aliphatic compounds by the A. aegerita peroxygenase

The regioselectivity of $A$. aegerita peroxygenase oxygenation reactions has been investigated here using $C_{12}$ to $C_{20}$ saturated and unsaturated fatty acids, the main products being monohydroxylated derivatives at the $\omega-1$ and $\omega-2$ positions. This regioselectivity is seemingly not chain-length dependent, since when length increased it did not shift between the $\omega-1$ and $\omega-2$ positions, or to contiguous positions. Hydroxylation of fatty acids has been thoroughly studied for P450s, and both similarities and differences with the peroxygenase reaction patterns can be observed [27,32-39]. P450BM-3 has been reported to convert lauric, myristic and palmitic acids to their $(\omega-1),(\omega-2)$ and $(\omega-3)$-hydroxy derivatives $[27,35]$ but, in contrast with that observed here, the percentage distribution of the regioisomers depends on the chain length (lauric and myristic acids being preferentially hydroxylated at $\omega-1$, while palmitic acid is mainly hydroxylated at the $\omega-2$ position). Regioselectivity changes in P450 hydroxylations suggest a "more selective" active site where the substrate carboxyl group is fixed at the entrance in such a way that the hydroxylation position depends on the length of the fatty acid chain (Arg47 being involved in fatty acid fixing at the P450BM-3 active site) $[26,40,41]$. In contrast, the active site of the $A$. aegerita peroxygenase seems "less selective" in substrate fixation, and hydroxylation is always preferentially produced at the $\omega-1$ and $\omega-2$ positions, which are more favorable than the $\omega$ position from the viewpoint of chemical reactivity.

With the A. aegerita peroxygenase, a highly regioselective reaction was found for myristoleic acid $\left(C_{14: 1}\right)$ that was hydroxylated at the $\omega-2$ position, and not at the $\omega-1$ position. A similar situation has been described in the oxidation of polyunsaturated arachidonic acid $\left(\mathrm{C}_{20: 4}\right)$ by P450BM-3 (yielding 99\% $\omega-2$ hydroxylation, $1 \%$ $\omega-3$ hydroxylation, and no reaction at $\omega-1)$ [36]. However, hydroxylation of saturated fatty acids by P450BM-3, although preferentially produced at the $\omega-2$ carbon, also yields substantial amounts of $\omega-1$ and $\omega-3$ hydroxylated products. Therefore, it seems that the arachidonic molecule imposes additional steric requirements resulting in highly selective hydroxylation by P450BM-3, and a similar situation would be produced in myristoleic acid oxidation by the peroxygenase.

Interestingly, a relationship between unsaturation and oxygenation regioselectivity was observed in the peroxygenase reactions with $C_{12}$ and $C_{16}$ fatty acids, the $\omega-1 / \omega-2$ ratio shifting from $\sim 0.8$ in the unsaturated to $\sim 1.5$ in the saturated fatty acids with the same chain length. A similar result has not been reported in P450 reactions. On the other hand, the $A$. aegerita peroxygenase hydroxylates unsaturated fatty acids in a similar manner as the saturated ones (preferential $\omega-1$ and $\omega-2$ oxygenation in all cases). No epoxidation has been detected in these reactions in contrast with P450BM-3 that caused both hydroxylation and epoxidation of unsaturated fatty acids $[33,36]$. The regioselectivity of the $A$. aegerita enzyme was also the same for fatty acid methyl esters, but these compounds were not hydroxylated by P450BM-3 [27].

In addition to main hydroxylation at $\omega-1$ and $\omega-2$ positions (and $\omega-3$ to $\omega-5$ low hydroxylation), hydroxylated derivatives at the terminal methyl group of the fatty acid chain were also identified that were subsequently converted to dicarboxylic acids, both present in low amounts. In contrast, no $\omega$ hydroxylation of fatty acids was detected in P450BM-3 reactions [27]. However, some particular P450s preferentially catalyze $\omega$ hydroxylations, at the most recalcitrant terminal methyl group [39].

The same regioselectivity observed for fatty acid oxygenation was observed in the peroxygenase reactions with fatty alcohols and medium-length alkanes, although the latter exhibited symmetric oxygenation at both ends of the molecule. P450BM-3 also shows similar regioselectivity with fatty alcohols and with fatty acids, but does not act on hydrocarbons.

Although the crystal structure of $A$. aegerita peroxygenase has not been reported yet, homology modeling using the L. fumago chloroperoxidase crystal structure [42] (PDB entry 1CPO) as template, suggests a more exposed heme than in P450s [40]. A wider active site would be able to accommodate the variety of substrates and perform the variety of oxygenation reactions that peroxygenases are able to catalyze. The crystal structure of the $A$. aegerita peroxygenase will be soon available [43], and this will provide the opportunity to perform a more detailed analysis of the structural bases of its regioselective hydroxylation activity.

Mechanisms of substrate oxygenation/oxidation as revealed using ${ }^{18} \mathrm{O}$ labeling

The most interesting catalytic property of the secreted $A$. aegerita heme-thiolate peroxidase is the transfer of oxygen to substrate molecules, which has been described as a peroxygenase activity. Reactions with $\mathrm{H}_{2}{ }^{18} \mathrm{O}_{2}$ performed in this study revealed that the oxygen introduced in the $\omega-1$ and $\omega-2$ hydroxylation of fatty acids originates from $\mathrm{H}_{2} \mathrm{O}_{2}\left(90 \%{ }^{18} \mathrm{O}\right.$-labeling in myristic acid hydroxylation) and not from $\mathrm{O}_{2}$, as in similar reactions catalyzed by P450BM-3 [26]. This difference is consistent with the different mechanisms for Compound I formation in both enzymes, as well as with the common mechanism of substrate hydroxylation by oxygen incorporation from the Compound I iron-oxo complex (see Eqs. (1) and (2) for peroxygenase reaction). ${ }^{18} \mathrm{O}$-labeling was very low (only $10 \%$ ) after hydroxyl oxidation to keto groups (during peroxygenase reaction with myristic acid) due to hydroxyl exchange with water (in the keto hydration-dehydration equilibrium) after the second hydroxylation yielding the gem-diol species.

The ${ }^{18} \mathrm{O}$-labeling reactions also showed that, in addition to its presence in the hydroxyl (and keto) groups, the $\mathrm{H}_{2}{ }^{18} \mathrm{O}_{2}$ oxygen also 


$$
\begin{aligned}
& \text { A } \mathrm{R}-\mathrm{CH}_{2}-\left(\mathrm{CH}_{2}\right)_{\mathrm{n}}-\mathrm{CH}_{2}{ }^{16} \mathrm{OH} \underset{\mathrm{H}_{2}{ }^{18} \mathrm{O}_{2}}{\stackrel{\mathrm{HTP}}{\longrightarrow}} \mathrm{R}-\mathrm{CH}_{2}-\left(\mathrm{CH}_{2}\right)_{\mathrm{n}}-{\underset{18}{\mathrm{CH}}}_{{ }^{16} \mathrm{OH}}^{/}
\end{aligned}
$$

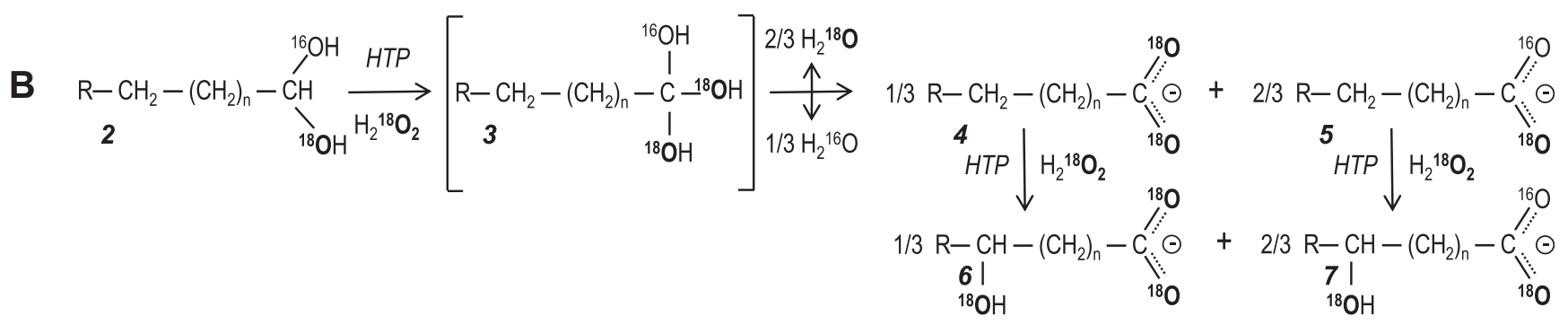

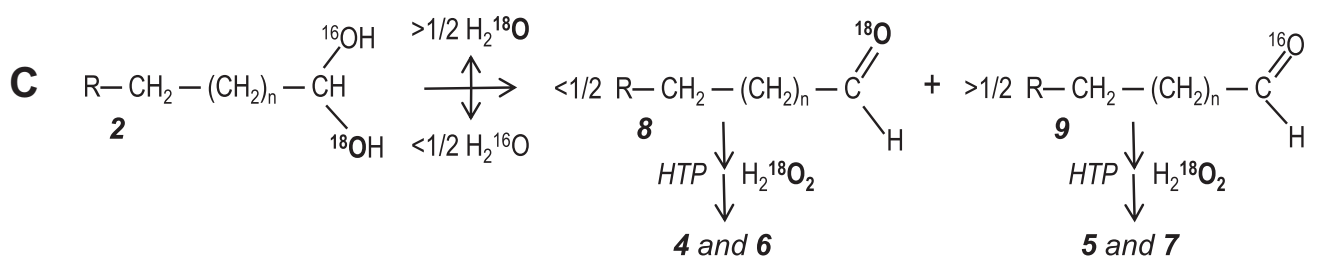

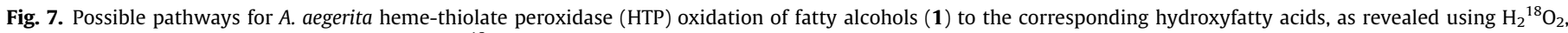

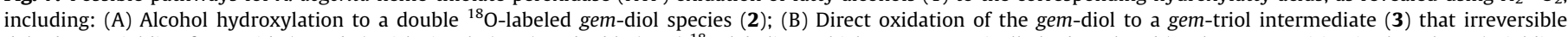

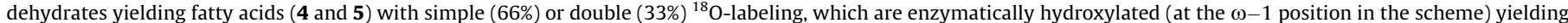

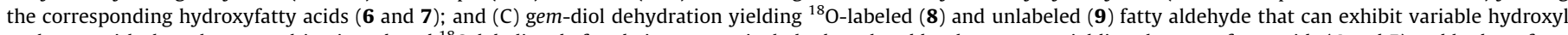

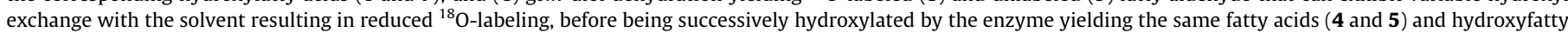

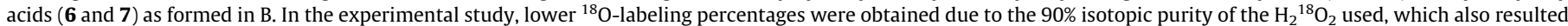
in a low percentage of monolabeled carboxylate.

incorporates into the carboxyl group during the oxidation of 1-tetradecanol to myristic acid (base peak $m / z 285$ ) and its $\omega-1$ and $\omega-2$ hydroxylated derivatives (Fig. 7). In the first case, ${ }^{18} \mathrm{O}-\mathrm{mono}-$ labeled $(\mathrm{m} / \mathrm{z} 287)$ and ${ }^{18} \mathrm{O}$-bilabeled $(\mathrm{m} / \mathrm{z} 289)$ fragments were observed in the mass spectrum of myristic acid, whose integration indicated $74 \%$ and $16 \%$ abundances, respectively. The ${ }^{18}$ O-labeling pattern was more complex in the two hydroxylated derivatives of myristic acid. Diagnostic ${ }^{18} \mathrm{O}$-monolabeled $(\mathrm{m} / \mathrm{z} 375$ and 361 in the $\omega-1$ and $\omega-2$ derivatives, respectively), ${ }^{18}$ O-bilabeled $(\mathrm{m} / \mathrm{z}$ 377 and 363), and ${ }^{18} \mathrm{O}$-trilabeled $(\mathrm{m} / \mathrm{z} 379$ and 365) fragments were observed, whose integration indicated 7-9\% simple labeling, $76 \%$ double-labeling, and 15\% triple-labeling. In both cases (myristic and hydroxymyristic acids from 1 -tetradecanol), ${ }^{18} \mathrm{O}$-labeling at the carboxyl group confirms that the oxygen incorporated during aliphatic alcohol oxidation to the corresponding acid is also supplied by $\mathrm{H}_{2} \mathrm{O}_{2}$ (peroxygenase activity). The relative abundances of the differently labeled products are related to the reaction mechanism commented below.

The first product of fatty alcohol oxidation by the peroxygenase will be a gem-diol from $C_{1}$ hydroxylation (Fig. 7A), which will be either directly hydroxylated (even at the nascent stage) yielding a gem-triol intermediate, irreversibly dehydrating to release the acid group (Fig. 7B); or first dehydrated to the corresponding aldehyde and then hydroxylated to the acid group (Fig. 7C). The predominant simple-labeling of the carboxyl group in fatty and hydroxyfatty acids (in the latter case accompanied by a second ${ }^{18} \mathrm{O}$ atom at the hydroxyl group) indicates the existence of such dehydration step, resulting in partial loss of the previously introduced ${ }^{18} \mathrm{O}$-labeling and formation of both ${ }^{16} \mathrm{O}$ and ${ }^{18} \mathrm{O}$ carboxylic group. The same has been shown in stepwise oxidations of ethanol by P450s [29,44]. The ${ }^{18} \mathrm{O}$-labeling patterns obtained, which are compatible with both oxidation pathways mentioned above, reveal no extensive hydroxyl exchange with the solvent at the aldehyde/gem-diol stage, which was hardly detectable in the chromatographic analysis (only alde- hyde traces found). In the former aspect, the reaction differs from $\mathrm{P} 450$ cascade oxidation of hexadecanol, where complete ${ }^{18} \mathrm{O}$-hydroxyl exchange with the solvent is produced before the final oxidation to palmitic acid, resulting in $\sim 2$ ratio between unlabeled and ${ }^{18} \mathrm{O}$ monolabeled palmitic acid [30]. Hydroxylation of the aldehyde form was the mechanism suggested in the $A$. aegerita peroxygenase oxidation of benzyl alcohol to benzoic acid, where, in contrast with that observed here, the aldehyde accumulates in substantial amount [45]. However, gem-triol intermediates are suggested in several P450-catalyzed reactions, including oxygenation of some of the aliphatic compounds investigated in the present study [30].

\section{Conclusions}

The new A. aegerita peroxidase combines $\mathrm{P} 450$ and typical peroxidase properties, resulting in activation by peroxide and catalysis of monooxygenase-type reactions (peroxygenase activity). Detailed GC-MS analyses revealed that this enzyme is able to oxidize/oxygenate a variety of aliphatic compounds. Therefore, the name "aromatic peroxygenase" should be substituted by "unspecific peroxygenase" and the corresponding entry (EC 1.11.2.1) has been accepted in the IUBMB Enzyme Nomenclature (www.chem.qmul.ac.uk/iubmb/enzyme). In spite of its classical peroxidative (i.e. non-oxygenase) activity, $\mathrm{H}_{2}{ }^{18} \mathrm{O}_{2}$ reactions indicated that the enzyme oxidizes aliphatic alcohols to the corresponding acids by enzymatic hydroxylation and dehydration reactions, taking advantage from its monooxygenase activity (also shown in fatty acid ${ }^{18} \mathrm{O}$ hydroxylation). Interestingly, most of the aliphatic oxygenations catalyzed by the $A$. aegerita peroxygenase (resulting in new hydroxy and keto derivatives) are regioselective taking place at the $\omega-1$ and $\omega-2$ positions, irrespective of the aliphatic chain length (myristoleic acid hydroxylation being only produced at the $\omega-2$ position). This regioselectivity, together with the self-sufficient 
oxygenase activity, make these new heme-thiolate peroxidases interesting biocatalysts for oxidative modification of different aliphatic compounds.

\section{Acknowledgments}

This study was funded by the PEROXICATS (KBBE-2010-4265397) and BIORENEW (NMP2-CT-2006-026456) EU-projects, and the ELLE (AGL2008-00709) and RAPERO (BIO2008-01533) Spanish MICINN projects co-financed by FEDER funds. J. Rencoret (IRNAS, Seville) is acknowledged for preliminary enzyme assays. E.D. Babot thanks the Spanish CSIC for a JAE fellowship.

\section{Appendix A. Supplementary data}

Supplementary data associated with this article can be found, in the online version, at doi:10.1016/j.abb.2011.08.001.

\section{References}

[1] R. Ullrich, M. Hofrichter, FEBS Letters 579 (2005) 6247-6250.

[2] R. Ullrich, J. Nuske, K. Scheibner, J. Spantzel, M. Hofrichter, Applied and Environmental Microbiology 70 (2004) 4575-4581.

[3] M.J. Nuell, G.H. Fang, M.J. Axley, P. Kenigsberg, L.P. Hager, Journal of Bacteriology 170 (1988) 1007-1011

[4] M. Hofrichter, R. Ullrich, M.J. Pecyna, C. Liers, T. Lundell, Applied Microbiology and Biotechnology 87 (2010) 871-897.

[5] R. Bernhardt, Journal of Biotechnology 124 (2006) 128-145.

[6] H. Li, in: A. Messerschmidt, R. Huber, T.L. Poulos, K. Wieghardt (Eds.) Handbook of metalloproteins, Wiley, Baffins Lane, UK, 2001, pp. 267-282.

[7] R. Ullrich, M. Hofrichter, Cellular and Molecular Life Sciences 64 (2007) 271293.

[8] M.J. Pecyna, R. Ullrich, B. Bittner, A. Clemens, K. Scheibner, R. Schubert, M. Hofrichter, Applied Microbiology and Biotechnology 84 (2009) 885-897.

[9] F.J. Ruiz-Dueñas, A.T. Martínez, in: E. Torres, M. Ayala (Eds.), Biocatalysts based on heme peroxidases, Springer-Verlag, Berlin, 2010, pp. 37-59.

[10] E. Aranda, M. Kinne, M. Kluge, R. Ullrich, M. Hofrichter, Applied Microbiology and Biotechnology 82 (2009) 1057-1066.

[11] M. Kinne, R. Ullrich, K.E. Hammel, K. Scheibner, M. Hofrichter, Tetrahedron Letters 49 (2008) 5950-5953.

[12] R. Ullrich, C. Dolge, M. Kluge, M. Hofrichter, FEBS Letters 582 (2008) 41004106

[13] M.G. Kluge, R. Ullrich, K. Scheibner, M. Hofrichter, Applied Microbiology and Biotechnology 75 (2007) 1473-1478.

[14] R. Ullrich, M. Hofrichter, in: M. Hofrichter (Ed.), The Mycota X: Industrial applications, Springer, Berlin, 2011, pp. 425-450.

[15] A. Gutiérrez, J.C. del Río, F.J. González-Vila, F. Martín, Journal of Chromatography A 823 (1998) 449-455.

[16] M. Hofrichter, R. Ullrich, M. Pecyna, M. Kinne, M.G. Kluge, E. Aranda, C. Liers, M. Poraj-Kobielska, G. Gröbe, B. Bittner, R. Schubert, K.E. Hammel, 16th International Conference on Cytochrome P450. (2009) 83-88.

[17] T.M. Makris, I. Denisov, I. Schlichting, S.G. Sligar, in: P.R. Ortiz de Montellano (Ed.), Cytochrome P450. Structure mechanisms and biochemistry, Kluwer Academic, New York, 2005.
[18] I. Matsunaga, T. Sumimoto, M. Ayata, H. Ogura, FEBS Letters 528 (2002) 90-94.

[19] F.J. Ruiz-Dueñas, A.T. Martínez, Microbiology and Biotechnology 2 (2009) 164177.

[20] P.R. Ortiz de Montellano, Cytochrome P450: structure, mechanism, and biochemistry, Kluwer Academic/Plenum, New York, 2005.

[21] M. Kinne, M. Poraj-Kobielska, S.A. Ralph, R. Ullrich, M. Hofrichter, K.E. Hammel, Journal of Biological Chemistry 284 (2009) 29343-29349.

[22] D.H. Anh, R. Ullrich, D. Benndorf, A. Svatos, A. Muck, M. Hofrichter, Applied and Environmental Microbiology 73 (2007) 5477-5485.

[23] F.J. Ruiz-Dueñas, E. Fernández, V. Sáez, M.J. Martínez, A.T. Martínez, in: G. Feijoo, M.T. Moreira (Eds.), Oxidative enzymes as sustainable industrial biocatalysts, USC (ISBN-13: 978-84-614-2824-3), Santiago de Compostela, 2010, pp. 92-97. www.biorenew.org/images/stories/OESIB_2010_Proceedings_ Book.pdf.

[24] D. Martínez, J. Challacombe, I. Morgenstern, D.S. Hibbett, M. Schmoll, C.P. Kubicek, P. Ferreira, F.J. Ruiz-Dueñas, A.T. Martínez, P. Kersten, K.E. Hammel, Proceedings of the National Academy of Sciences of the United States of America 106 (2009) 1954-1959.

[25] D. Martínez, L.F. Larrondo, N. Putnam, M.D. Gelpke, K. Huang, J. Chapman, K.G. Helfenbein, P. Ramaiya, J.C. Detter, F. Larimer, P.M. Coutinho, B. Henrissat, R. Berka, D. Cullen, D. Rokhsar, Nature Biotechnology 22 (2004) 695-700.

[26] A.W. Munro, D.G. Leys, K.J. McLean, K.R. Marshall, T.W.B. Ost, S. Daff, C.S. Miles, S.K. Chapman, D.A. Lysek, C.C. Moser, C.C. Page, P.L. Dutton, Trends in Biochemical Sciences 27 (2002) 250-257.

[27] Y. Miura, A.J. Fulco, Biochemistry and Biophysics. Acta-Lipids Lipid Metabolism 388 (1975) 305-317.

[28] A. Glieder, E.T. Farinas, F.H. Arnold, Nature Biotechnology 20 (2002) 11351139.

[29] L.C. Bell-Parikh, F.P. Guengerich, Journal of Biological Chemistry 274 (1999) 23833-23840.

[30] U. Scheller, T. Zimmer, D. Becher, F. Schauer, W.H. Schunck, Journal of Biological Chemistry 273 (1998) 32528-32534.

[31] H. Ouellet, S.H. Guan, J.B. Johnston, E.D. Chow, P.M. Kells, A.L. Burlingame, J.S. Cox, L.M. Podust, P.R.O. de Montellano, n. 77 (2010) 730-742.

[32] L.O. Narhi, A.J. Fulco, Journal of Biological Chemistry 261 (1986) 7160-7169.

[33] R.T. Ruettinger, A.J. Fulco, Journal of Biological Chemistry 256 (1981) 57285734.

[34] S.S. Boddupalli, R.W. Estabrook, J.A. Peterson, Journal of Biological Chemistry 265 (1990) 4233-4239.

[35] S.S. Boddupalli, B.C. Pramanik, C.A. Slaughter, R.W. Estabrook, J.A. Peterson, Archives of Biochemistry and Biophysics 292 (1992) 20-28.

[36] J.H. Capdevila, S.Z. Wei, C. Helvig, J.R. Falck, Y. Belosludtsev, G. Truan, S.E. GrahamLorence, J.A. Peterson, Journal of Biological Chemistry 271 (1996) 22663-22671.

[37] T. Oster, S.S. Boddupalli, J.A. Peterson, Journal of Biological Chemistry 266 (1991) 22718-22725.

[38] G. Truan, M.R. Komandla, J.R. Falck, J.A. Peterson, Archives of Biochemistry and Biophysics 366 (1999) 192-198.

[39] J.B. Johnston, H. Ouellet, L.M. Podust, P.R. Ortiz De Montellano, Archives of Biochemistry and Biophysics 507 (2011) 86-94.

[40] H.Y. Li, T.L. Poulos, Nature and Structural Biology. 4 (1997) 140-146.

[41] M.A. Noble, C.S. Miles, S.K. Chapman, D.A. Lysek, A.C. Mackay, G.A. Reid, R.P. Hanzlik, A.W. Munro, Biochemical Journal 339 (1999) 371-379.

[42] M. Sundaramoorthy, J. Terner, T.L. Poulos, Structure. 3 (1995) 1367-1377.

[43] K. Piontek, R. Ullrich, C. Liers, K. Diederichs, D.A. Plattner, M. Hofrichter, Acta Crystallography F 66 (2010) 693-698.

[44] F.P. Guengerich, C.D. Sohl, G. Chowdhury, Archives of Biochemistry and Biophysics 507 (2011) 126-134.

[45] M. Kinne, C. Zeisig, R. Ullrich, G. Kayser, K.E. Hammel, M. Hofrichter, Biochemical and Biophysical Research Communications 397 (2010) 18-21. 


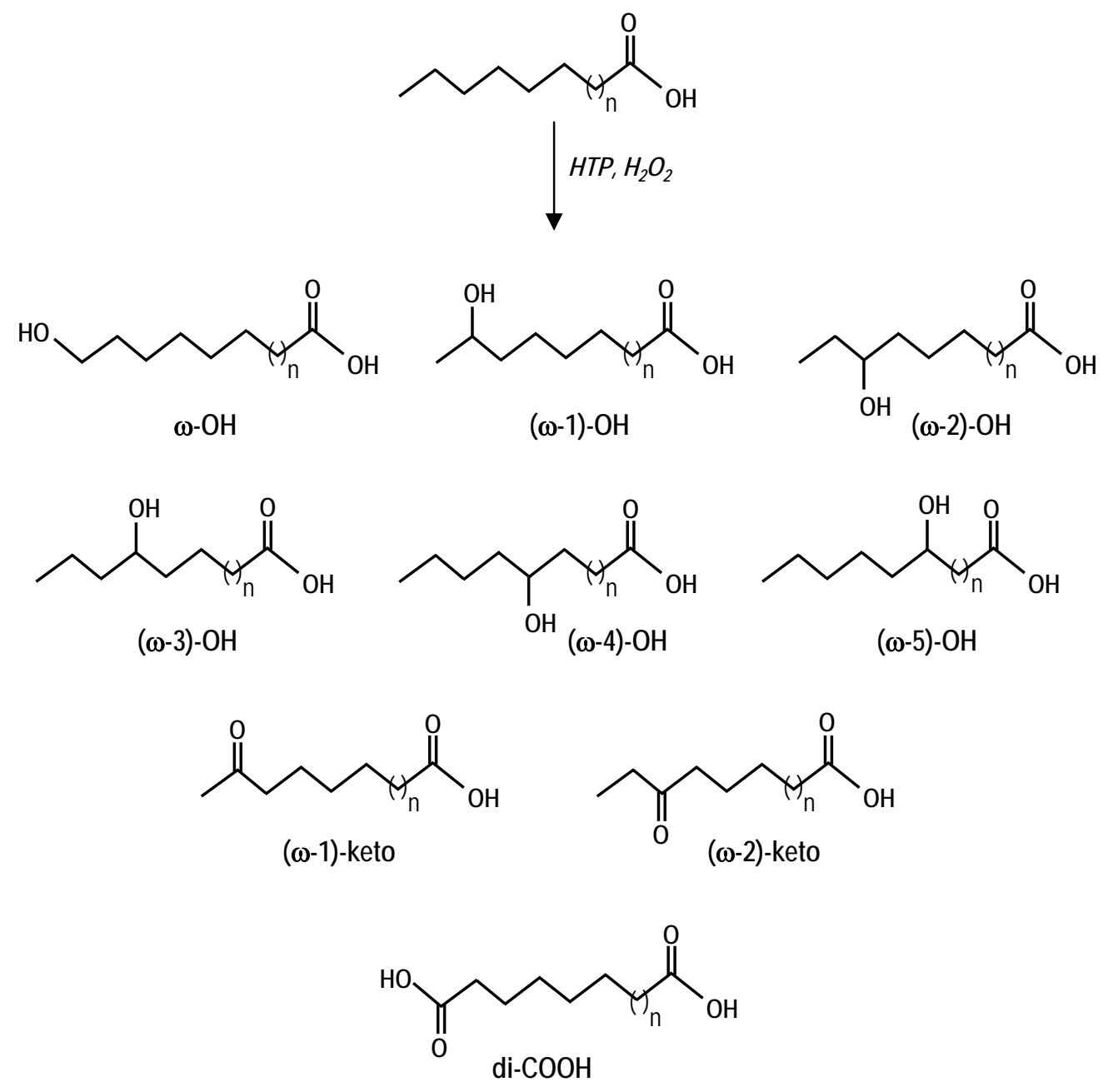

Fig. S1 Chemical structures of the main oxidation products identified in the peroxygenase reactions with fatty acids, including $\omega$ to $\omega-5$ hydroxylated derivatives, $\omega-1$ and $\omega-2$ keto derivatives, and dicarboxylic fatty acids. 

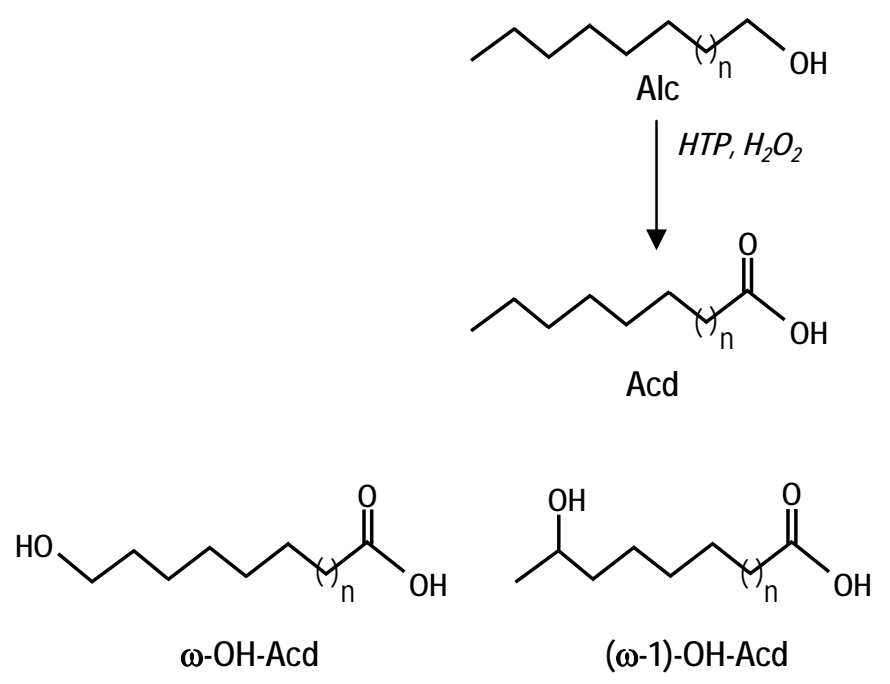<smiles>CCC(O)CCCCC(=O)O</smiles><smiles>CC(=O)CCCCCCC(=O)O</smiles>

$(\omega-1)-$ keto-Acd<smiles>CCC(=O)CCCCC(=O)O</smiles><smiles>CC(=O)CCCCCCO</smiles><smiles>CCC(=O)CCCCCO</smiles>

Fig. S2. Chemical structures of the main oxidation products identified in the peroxygenase reactions with fatty alcohols, including fatty acids (Acd) and their $\omega$ to $\omega-2$ hydroxylated, and $\omega-1$ and $\omega-2$ keto derivatives. Minor compounds such as $\omega-1$ and $\omega-2$ hydroxy and keto derivatives of the fatty alcohols (Alc) are also shown in brackets. 


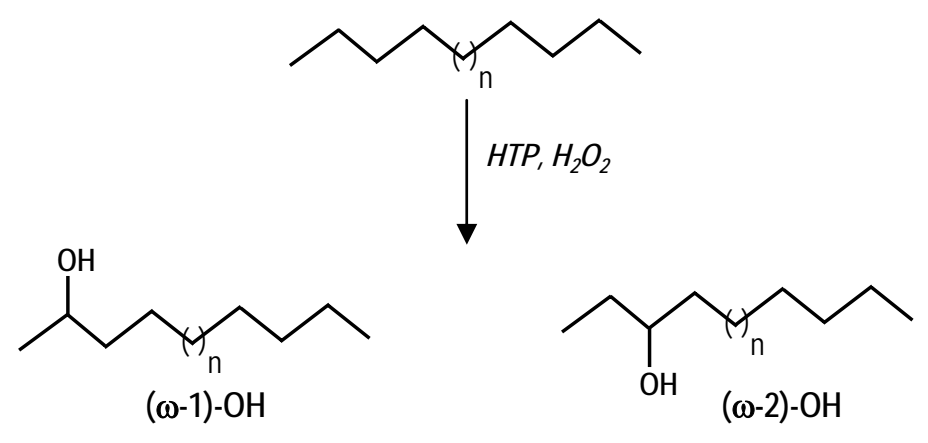<smiles>CC(O)CCCCCC(C)O</smiles>

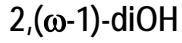<smiles>CCC(O)CCCCC(C)O</smiles>

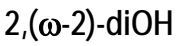<smiles>CCC(O)CCCC(O)CC</smiles>

3,( $(\omega-2)-d i O H$<smiles>CC(=O)CCCCCC(C)O</smiles>

( $\omega-1)-k e t o-2-O H$<smiles>CCC(=O)CCCCC(C)O</smiles>

( $\omega-2)-k e t o-2-O H$<smiles>CCC(=O)CC=NCC(O)CC</smiles>

( $\omega-1)-k e t o-3-O H$

( $\omega-2)-k e t o-3-O H$

Fig. S3. Chemical structures of the main oxidation products identified in the peroxygenase reactions with alkanes, including monohydroxylated (positions 2 and 3 ), and dihydroxylated (positions 2 and $\omega-1,2$ and $\omega-2$, and 3 and $\omega-2$ ) fatty

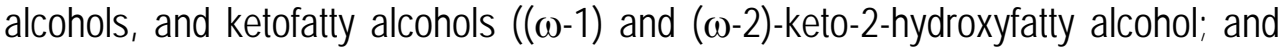
$(\omega-1)$ and ( $\omega-2)$-keto-3-hydroxyfatty alcohol). 

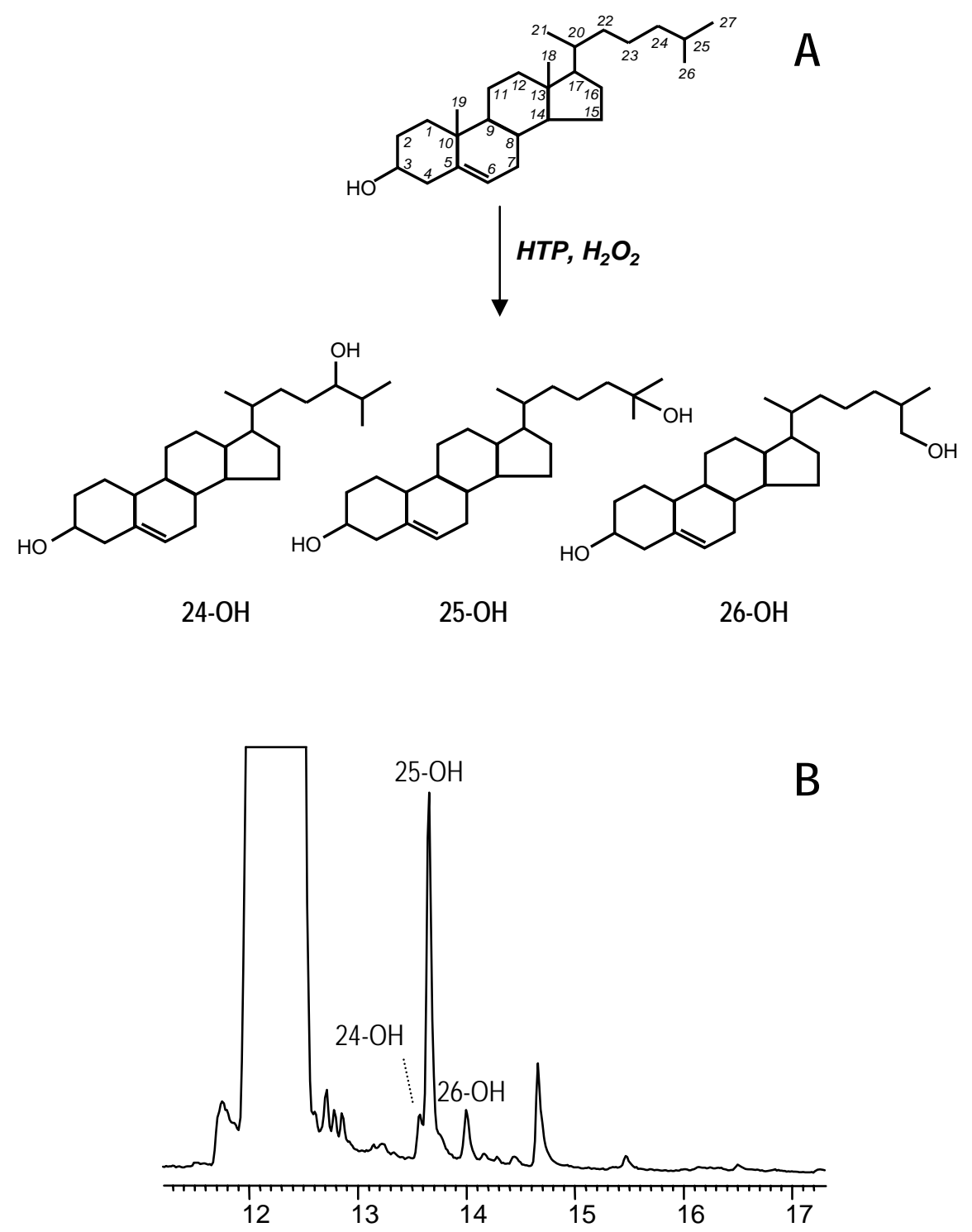

Fig. S4. Chemical structures of the main oxidation products identified in the peroxygenase reactions with cholesterol including 24-hydroxy, 25-hydroxy and 26-hydroxycholesterol (A), and GC-MS analysis of these products (B). 